\title{
Reply to: "Residency program trainee-satisfaction correlate with results of the European board examination in neurosurgery"
}

\author{
Paolo Cappabianca ${ }^{1}$
}

Received: 12 July 2016 / Accepted: 1 August 2016 / Published online: 12 August 2016

(C) Springer-Verlag Wien 2016

In my previous letter [1], I shortly and generously commented on the two articles about neurosurgical resident education in Europe $[2,3]$. Now the same group of authors, of whom I have an excellent consideration and I have the pleasure of personally know some of them, present one more survey about education in Europe [4], which I disagree with in terms of concepts, methods, and conclusions.

Time and efforts were spent to compare different categories, i.e. subjective evaluations of residency program trainees' satisfaction and objective tests, such as written and oral examinations of young neurosurgeons, not representative of the mean level of the residents in their respective countries. No doubt that there is the need of improving the mean quality among training centers, but educational systems cannot be judged on the basis of a controversial survey, retrieved from a selected group of people; the same authors affirm that the study presents consistent limitations that cannot be underestimated. In my opinion, these contributions are not scientifically adequate, as the population of the study represents only a small and not homogeneous sample of the European neurosurgical residents, and I will try to explain my opinion, starting with some of the author's statements.

"Substantial differences in neurosurgical training conditions throughout Europe exist...", and we were already aware of it.

"...The rationale was to investigate whether presumably a higher quality of training according to higher

Paolo Cappabianca

paolo.cappabianca@unina.it

1 Department of Neurosciences, Odontostomatological \& Reproductive Sciences, Division of Neurosurgery, Università degli Studi di Napoli Federico II, Via Pansini 5, 80131 Naples, Italy satisfaction rates in the previous survey in some European countries translated into measurably bettereducated residents....", and this is not in my opinion the best way to investigate the problem.

"The importance of providing excellent training conditions in Europe...", and such affirmation is predictable! “...The establishment of a European curriculum of contemporary neurosurgical knowledge... is a sensible issue...", and such affirmation is predictable too!

"...We could not establish any relationship between the amount of working time and the EBE-NS results...", which is in line with many American studies and observations about their working time limits for residents.

All of these statements reflect something we already knew and the amount of work produced by the authors sounds to me as too much noise for nothing. We agree that there is the need of continuously improving the quality of training centers. This was well known by the ancients, the School of Athens, Socrates, masters and disciples of the Schola Medica Salernitana [5], Frederick II, King of Sicily, and Holy Roman Emperor, who established in 1224 in Naples, the first public laic European University and many, many, many others, up to Malala Yousafzai, the Pakistani girl youngestever Nobel Prize laureate, who in her speech at the United Nations in 2013 stated "... One child, one teacher, one book and one pen can change the world. Education is the only solution. Education first...". Perhaps even the boy Daniel knows it, whose picture all the world has recently seen a toddler dreaming to be a doctor or a policeman, studying in the streets of Philippines under the light from the nearby McDonald's restaurant.

Our career is experiencing an actual revolution and it seems that it will be never over. We don't have to wait decades or generations anymore to participate in social 
and/or cultural changes: today, the essence of knowledge doubles every 5 years. This process has become very fast, almost hectic. So we find out nothing new when we consider education as crucial and critically analyze the educational aspects of different people and cultures, the issue is how we do it.

In order to make real the amelioration of the teaching process and effective the objective learning, it is necessary to speak a common language, and have similar training programs and education systems; all of this has not yet happened in Europe. Unlike the United States, Europe is not a unique community with the same language, with the same school system, with the same laws, etc., etc. Europe is a set of a multitude of people, with different origins, costumes, languages, traditions, schools, governments, and societies.

Sports, soccer for instance, is a metaphor for life. Teutonic rules, scheme, computer analysis are not sufficient to win the Champions League, men from different schools and different countries can provide an unexhausted fuel. In soccer as in medicine, others, often, give birth to talents, breed them and, then, wealthier nations buy them. The Bayern München Football Club, for instance, a team composed of many stars, is not the European Champion and is in the above said condition. Frequently, it happens that less productive countries' teams prevail where the commitment and the rule are not so strict, not just muscular, teams where there is place for the Latin genius. "... Once, during the training, the coach wanted me to hit the ball with the head anticipating my mate who was playing as opposing defender... I stopped, let go the last ball, did not even jump. The coach demanded explanations. I only said: "Coach, the head serves to think, not to hit the ball" ... That day I did not hit the ball because I didn't want to risk to lose not even a single thought." [6]

\section{What does this mean:}

- first it means that differences are necessary and are a treasure;

- it means that different people often have different needs;

- it means that in each single country there are excellent and/ or lesser training and educational centers;

- it means that nature, politics, and economy determine these conditions of inequality;

- it means that a horizontal, icy analysis, a survey with a debilitating recruitment bias, that takes some good and willing from scattered schools and then gathers from their subjective satisfaction responses the value and needs of the schools is an unhappy activity.

In my opinion, this survey and the previous two of the same group of authors do not enrich the scientific community; they do not provide any missing information, but very selected data, not suitable, indeed.

Many trainees from "the countries that scored significantly less" are regularly employed in other European countries, which means that:

- the trainees are adequately trained to be employed in countries different than those they were born;

- the accepting countries earn competencies without spending money for their education;

- there is an occupational issue and different working opportunities in the different European countries.

It seems to me that a sociological and political issue rather than an educational problem exists! It seems that rich people are gaining richness more and more and distances and differences increase rather than aiming at an overall improvement in a community of states, but I do not think that our European Neurosurgical Journal is the place to debate political affairs and perspectives, and I think that differences may be a great richness, if correctly understood and corrected, when necessary. Our community does not need votes or rankings, as in a race, but rather needs to be enriched with knowledge and competencies to be able to improve our daily work of teachers, and the attitudes and skills of our trainees. The three surveys of this group of authors fail, in my opinion, to contribute to an understanding of the real situation and needs of our educational systems, and divide rather that joining.

In our limited experience, we spent many years to develop, promote, and teach a surgical technique - although trivial - and each time we learned by those who came to learn, all over the world. I hope to have never divided, but instead I tried to join, even those who practiced, for example, at the dawn of the 2000 s, a lateral rhinotomy for a pituitary adenoma. Today we share the same path!

The 2015 EANS Congress in Madrid has been a success. Athens 2016 is the EANS Meeting we all are working at to make it another success. Venice 2017 has high expectations for the ancient lineage of the location and guest. Perhaps Spain, Greece, Italy, and other countries deserve better consideration than the one given by these surveys. Even 20th-century recent history teaches us that the harmony among various ethnic groups and schools wins on those who claim to be the best.

\section{Compliance with ethical standards}

Conflict of interest No grants or funding have been received for this study. The author declares no affiliations with or involvement in any organization or entity with any financial interest in the subject matter or materials discussed in this manuscript. 


\section{References}

1. Cappabianca P (2016) Reply to: "Neurosurgical resident education in Europe - results of a multinational survey". Acta Neurochir (Wien) 158(4):621-622. doi:10.1007/s00701-016-2730-7

2. Stienen MN, Netuka D, Demetriades AK, Ringel F, Gautschi OP, Gempt J, Kuhlen D, Schaller K (2016) Neurosurgical resident education in Europe-results of a multinational survey. Acta Neurochir (Wien) 158(1):3-15. doi:10.1007/s00701-015-2632-0

3. Stienen MN, Netuka D, Demetriades AK, Ringel F, Gautschi OP, Gempt J, Kuhlen D, Schaller K (2016) Working time of neurosurgical residents in Europe-results of a multinational survey. Acta Neurochir (Wien) 158(1):17-25. doi:10.1007/s00701-0152633-Z

4. Stienen MN, Netuka D, Demetriades AK, Ringel F, Gautschi OP, Gempt J, Kuhlen D, Schaller K (2016) Residency program traineesatisfaction correlate with results of the European board examination in neurosurgery. Acta Neurochir (Wien): in press

5. de Divitiis E, Cappabianca P, de Divitiis O (2004) The "schola medica salernitana": the forerunner of the modern university medical schools. Neurosurgery 55(4):722-744, discussion 744-725

6. Masullo M (2016) Il tassista di Maradona. Rizzoli, Napoli 